\title{
Quality of life in community-dwelling Dutch elderly measured by EQ-5D-3L
}

\author{
Marie-Josée J. Mangen ${ }^{1 *}$, Marieke Bolkenbaas ${ }^{1}$, Susanne M. Huijts ${ }^{1,2}$, Cornelis H. van Werkhoven', \\ Marc J. M. Bonten ${ }^{1,3}$ and G. Ardine de Wit ${ }^{1}$
}

\begin{abstract}
Background: We aimed to evaluate health status and associated factors in community-dwelling elderly in the Netherlands.

Methods: Participants from a placebo-controlled double-blind randomized controlled trial conducted in the Netherlands were invited at the time of enrolment to participate in this study. Data were collected on comorbidities, socio-demographic background and health status, using EQ-5D-3L instrument. EQ-5D-3L summary index values (EQ-5D-indices) was derived using Dutch tariff. Regression analysis was conducted to identify factors associated with EQ-5D-indices and visual analogue scale (EQ-VAS).

Results: 48,634 elderly ( $\geq 65$ years) were included. The most frequently reported complaint was pain/discomfort (29.4\%), but for the elder elderly (i.e. $\geq 85$ years) it was mobility (52.9\%). The proportion of persons reporting (multiple) problems increased with age from 31.5\% for 65-69 years old subjects to 65.9\% for elder elderly. The mean EQ-5D-indices and EQ-VAS decreased with age from 0.94 and 84, respectively in those 65 to 69 years old to 0.86 and 76 , respectively, in $\geq 85$ years old subjects. Increasing age, female gender, low education, geographic factors and comorbidities were associated with impaired health status.
\end{abstract}

Conclusions: Within community-dwelling elderly large differences in health status exist. Impairment increases rapidly with age, but health status is also associated with socio-demographic variables and comorbidities.

Trial registration: ClinicalTrials.gov, NCT00812084.

Keywords: Health-related quality-of-life, Health status, EQ-5D-3L, Elderly, Community-dwelling, The Netherlands

\section{Background}

In 2050 more than $25 \%$ of the Dutch population will be aged 65 years and older [1]. With an ageing population and rising health expenditure, preventing illness in elderly becomes more important. Measuring the health of the population is therefore important to guide health policy decisions, normally aimed at improving health and reducing socioeconomic differences in health. The EQ-5D-3L is one of most commonly applied generic health-related quality-of-life instrument $[2,3]$, and is suitable for measuring health status within an elderly population $[4,5]$. There are six publications (i.e., [6-11])

\footnotetext{
* Correspondence: m.j.j.mangen@umcutrecht.nl

${ }^{1}$ Julius Center for Health Sciences and Primary Care, University Medical

Center Utrecht, Str 6.131 room 7.115, Heidelberglaan 100, Utrecht 3584, CX,

The Netherlands

Full list of author information is available at the end of the article
}

reporting quality-of-life data using the EQ-5D instrument for Dutch elderly. Stolk et al. [6] reported EQ-5D3L-index and EQ-visual analogue scale (VAS) scores for three age-classes (i.e. $65-69,70-75$ and $\geq 75$ years) and both sexes based on 254 respondents. Furthermore, Timmers et al. [7] reported the EQ-5D-3L index values for elderly in two age-classes of 50-69 and 70-97 years based on 1311 respondents and using data from the second Dutch National Survey of General Practice (DNSGP-2) conducted in 2001 [9]. Further used Hoeymans et al. [9] the DNSGP-2 cohort to present the EQ-domains for elderly (1008 respondents) in three age-classes (i.e. 60-69, 70-79 and $\geq 80$ ) and both sexes. Szende et al. [8] reported quality-of-life (i.e. EQ-domains, EQ-5D index and EQ-VAS scores) for two age-classes (i.e. 65-74 and $\geq 75$ years) based on 450 respondents, using data from the European 
Study of the Epidemiology of Mental Disorders (ESEMeD) study collected between 2001 and 2003 [12]. Further used König et al. [10] the ESEMeD study, to report on the EQ-domains and EQ-VAS scores of advanced elderly (i.e., $\geq 75$ years) in six European countries, including the 164 Dutch responders aged 75 and older. A more recent study (data collected in 2012), reported EQ-5D-5 L index scores for the agegroups $60-70$ and $\geq 70$ years based on 281 respondents [11]. Important determinants for health identified in earlier studies were age (e.g. $[8,13-19])$, gender (e.g. $[8,13-19])$ and education (e.g. $[8,13,14,16,19])$. Detailed comorbidity data were in most of these studies lacking.

The aim of this study was to evaluate health status and associated factors in community-dwelling elderly in the Netherlands, using the EQ-5D-3L instrument.

\section{Methods \\ Data collection}

Data presented in the current study was collected from the "Cost, Health status and Outcomes of communityacquired pneumonia (CAP)" (CHO-CAP) source population, which consisted of community-dwelling elderly ( $\geq 65$ years) in the Netherlands. The aim of the CHOCAP study was to prospectively collect information on health outcomes and costs of CAP cases in a nested matched cohort. Full details on study design are provided elsewhere [20]. The CHO-CAP study was executed in parallel to the "Community-Acquired Pneumonia immunization Trial in Adults" (CAPiTA), a placebo-controlled double-blind randomized clinical trial evaluating the effectiveness of a 13-valent conjugate pneumococcal vaccine in 84,496 community-dwelling elderly in the Netherlands [21, 22]. Overall 72,074 CAPiTA participants were invited at the time of vaccination (November 2008-January 2010) to participate in the CHO-CAP study. The remaining 12,422 subjects (14.7\%) participating in CAPiTA were vaccinated previous to the start of the CHO-CAP study. At the time of vaccination, subjects reveived written information on the CHO-CAP study together with a questionnaire. They were asked to provide information on their current health status to complement socio-demographic and comorbidity details collected in CAPiTA, and to return the questionnaire together with a signed informed consent in a pre-stamped envelope. Those who did $(n=48,634)$ formed the CHO-CAP source population and were eligible for participation in a nested matched cohort to prospectively collect information on health outcomes and costs of CAP cases. Key eligibility criteria were: no previous pneumococcal vaccination and absence of protocol-defined immunocompromising conditions (for full details see [22] and Additional file 1: Section 1). In this study we used the data collected from the CHOCAP source population and the self-reported comorbidities collected within the CAPiTA-trial [22].

\section{Health status using the EQ-5D-3L instrument}

The EQ-5D-3L instrument was developed by the Euroqol group [2]. The instrument consists of two parts, the EQ$5 \mathrm{D}$ descriptive system and the EQ-visual analogue scale (VAS). The EQ-VAS records the participant's self-reported health on a VAS from 0 to 100, with anchor points being labelled as "Best imaginable health state" (100) and "Worst imaginable health state" (0). The EQ-5D-3L descriptive system consists of five domains (i.e. mobility, self-care, usual activities, pain/discomfort and anxiety/depression) and three levels of functioning (i.e. no problems, some problems or severe problems) [2]. The EQ-5D-3L health states were scored with the Dutch value set [23], to obtain EQ-5D-3L summary index values (EQ-5D-index) standardized from 0 (representing death) to 1 (representing full health), with negative values representing states worse than death $[2,23]$.

\section{Socio-demographic and comorbidity data}

Self-reported socio-demographic data were age, gender, race, living situation and postal code. Self-reported comorbidities included asthma, diabetes with and without use of insulin, heart disease, liver disease, lung disease, history of splenectomy, history of stroke and/or myocardial infarction and smoking behaviour. The postal code was used to determine the geographic region of participants (i.e. east, south, north and west). The Nomenclature of Territorial Units for Statistics (NUTS) was used to determine the regions $[24,25]$.

\section{Data analysis}

The percentage reporting problems in one or more domains of EQ-5D, the EQ-5D-indices and the EQ-VAS were examined. Differences between age-groups were tested using Chi-square test for categorical outcomes and Mann-Whitney U test or Kruskal Wallis test $(\geq 2$ groups) for continuous outcomes. Results were presented by predefined age-groups (65-69; 70-74; 75-79; $80-84$ and 285 ) and by sex (male and female).

Furthermore, a stepwise linear regression model was used to identify factors associated with quality-of-life, with EQ-5D-indices and EQ-VAS as dependent variable respectively. Explanatory variables were age (continuous variable), gender, education, region, smoking, having comorbidity $x$ ( $x$ stands for asthma, diabetes with and without use of insulin, heart disease, liver disease, lung disease and history of splenectomy) and/or having a previous cardiovascular event $y$ ( $y$ stands for stroke, and myocardial infarction). Analyses were conducted using SPSS version 22 . 


\section{Results}

The CHO-CAP questionnaire was distributed to 72,074 CAPiTA-participants. The questionnaire and informed consent were received from 48,634 subjects, corresponding to a response rate of $67.5 \%$ of those invited to participate (see Additional file 1: Figure S1).

The majority of participants were male (57\%), were aged between 65 and 74 years (69.9\%), were low educated (41.9\%), lived in the west (36.6\%) and had no comorbidities (54.8\%), see Table 1 and Additional file 1: Table S1. Women, the very elderly, and lower educated elderly were underrepresented in the study population (Table 1). Nonresponders had more comorbidities than those included in the study (see Additional file 1: Table S1).

The proportion of elderly with no problems, some problems and severe problems of functioning by domain and by age-group and sex is shown in Fig. 1a with underlying data in Additional file 1: Table S2. The population profile by age-group and sex, expressed as percentage reporting problems in one or several domains is presented in Fig. 1b and in Additional file 1: Figure S2. In most age-classes, pain/discomfort was the most frequently reported complaint, ranging from 24.1\% (age-group 65-69) to 38.0\% (age-group 80-84). Relatively few respondents had problems with self-care,

Table 1 Characteristics of the study population compared to the elderly (i.e. $\geq 65$ years) Dutch population

\begin{tabular}{|c|c|c|}
\hline & $\begin{array}{l}\text { CHO-CAP-study } \\
(n=48,634)\end{array}$ & $\begin{array}{l}\text { General Dutch elderly } \\
\text { population in } 2010^{\mathrm{a}} \\
(n=2,538,328)\end{array}$ \\
\hline \multicolumn{3}{|l|}{ Sex (\%) } \\
\hline Male & 57.2 & 43.7 \\
\hline Female & 42.8 & 56.3 \\
\hline \multicolumn{3}{|l|}{ Age (\%) } \\
\hline 65-69 years & 39.9 & 30.6 \\
\hline $70-74$ years & 30.0 & 24.4 \\
\hline $75-79$ years & 18.3 & 19.5 \\
\hline $80-84$ years & 8.7 & 13.8 \\
\hline$\geq 85$ years & 3.1 & 11.7 \\
\hline \multicolumn{3}{|l|}{ Education $(\%)^{\mathrm{b}}$} \\
\hline Low & 41.9 & 56.2 \\
\hline Middle & 33.8 & 28.2 \\
\hline High & 23.0 & 15.6 \\
\hline \multicolumn{3}{|l|}{ Region (\%) } \\
\hline North & 6.2 & 11.2 \\
\hline East & 24.7 & 20.6 \\
\hline West & 36.6 & 45.1 \\
\hline South & 32.4 & 23.1 \\
\hline
\end{tabular}

${ }^{a}$ Figures from the Dutch population are derived from Statistics Netherlands for the year 2010 [29]

${ }^{\mathrm{b}}$ Education level: $1.2 \%$ missing data ranging from 1.4\% (age-group 65-69) to 5.6\% (agegroup $80-84$ ). In the eldest elderly ( $\geq 85$ years), mobility was the most frequently reported problem (52.9\%), while anxiety/depression was least frequently reported as problem (8.1\%). The proportion of persons reporting problems, and the number of domains with problems is rising with increasing age (see Figs. 1a-1b). In all age-groups and for all five domains, women reported more problems than men (see Figs. 1a-1b).

Mean population EQ-VAS and mean EQ-5D-index values were 82 and 0.92 , respectively. Male respondents had both, higher EQ-VAS and higher EQ-5D-index values than female respondents, namely 82 versus 81 and 0.93 versus 0.90 respectively, see Fig. 2 and Additional file 1: Tables S3 and S4. Both mean EQVAS and EQ-5D-index values decreased significantly with increasing age from 84 to 0.94 in the 65-69 age-group to 76 and 0.86 in the elder elderly, respectively (Fig. 2 and Additional file 1: Tables S3 and S4).

Next to female gender $(\beta=-0.40)$ and increasing age ( $\beta$ : -0.003$)$, lower education $(+0.011$ for medium $/+0.20$ for high education), smoking (-0.021), having a comorbidity (e.g. asthma: - 0.16; diabetes using insulin: -0.027) and/or a previous cardiovascular event (stroke: -0.56 ; myocardial infarct -0.29 ) and living in the southern region $(-0.005)$ were negatively associated with EQ-5D index values (see Table 2). Similar findings were found for EQVAS. For more details see Table 2.

\section{Discussion}

Within elderly people, large quality-of-life differences exist. The proportion reporting problems was rising with increased age, as was also the proportion of persons reporting problems in more than one domain. For most age-groups and both sexes, pain/discomfort was the most frequently reported complaint. Similar to other studies, self-care problems were reported least frequent $[9,19,26]$. Only in the oldest elderly, mobility problems were more frequently reported than pain/discomfort, while anxiety/depression was the least frequent reported problem. Similar to other studies [8-10, 13-19] female sex was associated with more problems on each of the five EQ-5D domains, and consequently also with a lower EQ-5D-index compared to men. Increasing age, female sex, lower education, smoking, having a comorbidity and/or a previous cardio-vascular event, but also geographic factors such as living in the southern region of the Netherlands and living in an urban area, were all associated with lower EQ-5D health status.

The use of national tariffs, different response styles due to social and cultural background and different reference levels all influence the final EQ-5D-indices score $[10,13,15,27]$. According to Szende et al. [8] it is mainly the prior living standards of a country explaining 


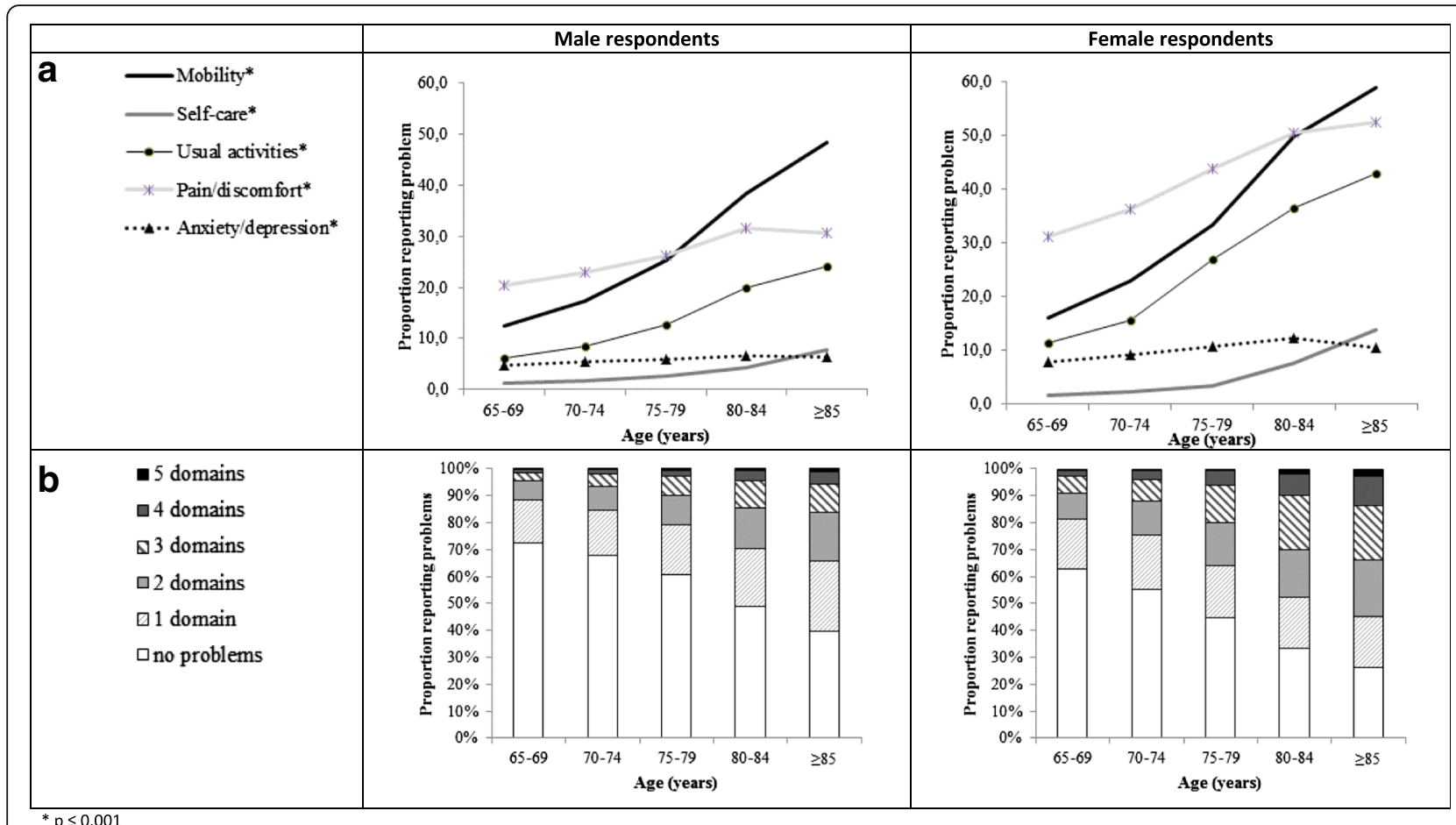

Fig. 1 Profile of the population: Percentage reporting any problems per domain (a) and percentage reporting number of domains with problems (b) by age-group and sex, respectively. ${ }^{*} p \leq 0.001$

the observed cross-country differences in general health. Therefore, a direct comparison with other countries is hampered by these important cross-country differences in background. König et al. [10], who compared the health status of elderly in six European countries, namely Belgium, France, Germany, Italy, the Netherlands, and Spain, noted that the Netherlands was the country with the lowest proportion of respondents reporting any problems. This corresponds to the findings of Konerding et al. [13] who studied the health status in adult type 2 diabetes patients in six European countries, and who noted that the Dutch respondents reported fewer problems in four of the five domains, and only Finland reported fewer problems with depression and/or anxiety. In our study, the tendency of reporting problems, increased with age and was associated with being female and having a low education, similar to other studies (e.g. [6, 8-10, 13-16, 19, 27]). Pain/discomfort was the most frequently reported problem, but in the eldest elderly problems with the mobility domain occurred most frequently, similar to findings in a

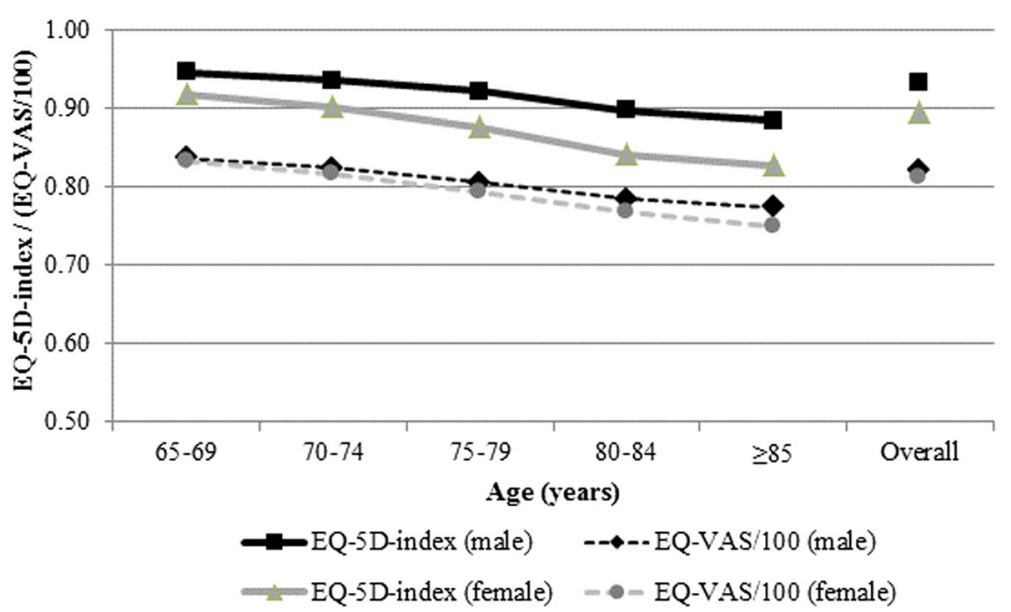

Fig. 2 Mean population EQ-VAS and mean EQ-5D-3L-index by age-group and sex. Note: EQ-VAS and EQ-5D-3L indices were significantly different between age-group and sex $(p>0.01)$ 
Table 2 Factors associated with health status, with EQ-5D-indices and EQ-VAS as dependent variables, respectively

\begin{tabular}{|c|c|c|}
\hline & \multicolumn{2}{|c|}{$\begin{array}{l}\text { Un-standardised regression coefficients } \\
\text { ( } p \text {-value) }\end{array}$} \\
\hline & $\begin{array}{l}\text { EQ-5D-indices } \\
\left(R^{2}=0.090\right)\end{array}$ & $\begin{array}{l}\text { EQ-VAS } \\
\left(R^{2}=0.098\right)\end{array}$ \\
\hline Constant & $1.181(0.000)$ & $106.683(0.000)$ \\
\hline Age (in years) & $-0.003(0.000)$ & $-0.308(0.000)$ \\
\hline Gender (male = reference) & $-0.040(0.000)$ & $-1.672(0.000)$ \\
\hline \multicolumn{3}{|l|}{ Education (low = reference) } \\
\hline Moderate & $0.011(0.000)$ & $0.462(0.000)$ \\
\hline High & $0.020(0.000)$ & $0.575(0.000)$ \\
\hline \multicolumn{3}{|l|}{ Region (west = reference) } \\
\hline North & $0.001(0.606)$ & $0.050(0.832)$ \\
\hline East & $-0.002(0.093)$ & $-0.183(0.191)$ \\
\hline South & $-0.005(0.000)$ & $-0.768(0.000)$ \\
\hline Smoking & $-0.021(0.000)$ & $-1.232(0.000)$ \\
\hline Asthma & $-0.016(0.000)$ & $-1.932(0.000)$ \\
\hline Diabetes - using insulin & $-0.027(0.000)$ & $-3.125(0.000)$ \\
\hline Diabetes - no insulin & $-0.010(0.000)$ & $-1.697(0.000)$ \\
\hline Heart disease & $-0.012(0.000)$ & $-1.633(0.000)$ \\
\hline Lung disease & $-0.018(0.000)$ & $-2.386(0.000)$ \\
\hline Liver disease & $-{ }^{a}$ & $0.418(0.031)$ \\
\hline Previous stroke & $-0.056(0.000)$ & $-5.928(0.000)$ \\
\hline Previous myocardial infarct & $-0.029(0.000)$ & $-4.563(0.000)$ \\
\hline
\end{tabular}

${ }^{a}$ Not significant in univariate analysis therefore not included in multivariate analysis

Dutch study of Hoeymans et al. [9]. Anxiety/depression was reported least frequent like, in other studies [8-10]. Overall, our large sample of respondents appeared to report slightly fewer problems in most domains of EQ-5D compared to previous studies conducted in Dutch elderly [6-8]. The relative largest differences were found for anxiety/depression. According to Szende et al. [8] 9.9\% and $12.5 \%$ of the $65-74$ years and $\geq 75$ years old reported to be moderately or extremely anxious or depressed, and according to Hoeymans et al. [9] this was $11.8 \%$ (65-79 years) and $13.6 \%$ ( $\geq 80$ years). In our population only $6 \%$ reported to be moderately or extremely anxious or depressed, similar to König et al. [10]. Comparing the mean EQ-5D-index scores found in other Dutch studies, our estimates were slightly higher [6-8] which may be explained from the fact that our sample consisted of a relatively fit and healthy population participating in a clinical trial, with more males and higher education level compared to the general population.

Social and cultural background differences mostly found between countries [10,13, 15, 27] could be confirmed to exist also within a small country such as the Netherlands. In particular, respondents living in Southern Netherlands tend to have a slightly lower health status than those living in other regions. This is a consistent finding in many studies on within country differences in health status [28]. The different cultural and social background and history of the Southern part of the country seems to have an impact up to today.

Strength of our study is the large study population of elderly persons (i.e. $\geq 65$ years), allowing stratification by gender and five age-groups. A further strength of the current study is the data availability of prevalent chronic comorbidities and/or a previous cardio-vascular event.

One of the limitations of our study was that we had a sample with a higher percentage of men than all other studies and furthermore our population had a higher education level than the general population. By definition, immunocompromised persons were excluded, as this was an exclusion criterion in the CAPiTA-trial [21, 22]. Our study population was therefore probably fitter and healthier than the general Dutch elderly population.

\section{Conclusion}

Within community-dwelling elderly large differences in health status exist. Impairment increases rapidly with age, but health status is also associated with sociodemographic variables and comorbidities.

\section{Additional file}

Additional file 1: section 1- Inclusion and exclusion criteria. Figure S1 - Flow chart of the CHO-CAP population. Table S1 - Baseline characteristics of non-responders and CHO-CAP participants. Table S2 - Proportion of three levels of functioning by domain by age-group as reported by male and female respondents, respectively. Figure $\mathbf{S 2}$ - Profile of the population (all respondents): Percentage reporting problems by agegroup. Table S3 - EQ-VAS scores by age for male, female and total respondents, respectively. Table S4 -EQ-5D-3L-indices by age for male, female and total respondents, respectively. (DOCX $102 \mathrm{~kb}$ )

\section{Abbreviations}

CAP: Community-acquired pneumonia; CAPiTA: Community-acquired pneumonia immunization trial in adults; CHO-CAP: Costs, health status and Outcomes of community-acquired pneumonia; EQ-5D: Euroqol group EQ5D-3L instrument; EQ-5D-indices: Euroqol group EQ-5D-3L summary index values; EQ-VAS: Euroqol group visual analogue scale; MAUIs: Multi-attribute utility instruments; NUTS: Nomenclature of territorial units for statistics; QALY: Quality-adjusted life years

\section{Acknowledgments}

The authors would like to thank all "Costs, Health status and Outcomes of community-acquired pneumonia (CAP)" (CHO-CAP) participants for their participation. The "Community-Acquired Pneumonia immunization Trial in Adults" (CAPiTA) team and the CHO-CAP-team from Julius Clinical B.V. in Zeist are acknowledged for their logistic support during the data collection. Bente S. Dikken, medical student at University Medical Center Utrecht, is acknowledged for some preliminary data cleaning. The CHO-CAP study is made possible by an unrestricted grant from Wyeth Pharmaceuticals, which was acquired by Pfizer Inc. in October 2009, to the University of Medical Centre of Utrecht.

\section{Funding}

The CHO-CAP study is made possible by an unrestricted grant from Wyeth Pharmaceuticals, which was acquired by Pfizer Inc. in October 2009, to the University of Medical Centre of Utrecht. 
The Sponsor had no role in the design, analysis, interpretation of the data, or the writing of the manuscript. The Sponsor did review a penultimate version of the manuscript.

\section{Availability of data and materials}

Data available from the first author upon request.

\section{Authors' contributions}

MJJM, GAdW and MB designed the study. MJJM performed the statistical analysis and drafted the manuscript. GAdW and MB supervised this research project. MB, SMH and CHvW organized data acquisition of the CAPiTA study. All authors critically reviewed and approved the manuscript.

\section{Competing interests}

Bolkenbaas reports receipt of presentation honorary from Pfizer. Bonten reports receipt of research funding from Pfizer, and service on the "Community-Acquired Pneumonia immunization Trial in Adults" (CAPiTA) European Expert Meeting. Huijts reports receipt of financial support for printing her PhD thesis from Pfizer. Mangen declares fees paid by GSK to the institution for participating in model building. Van Werkhoven reports service in a Pfizer Advisory Committee. De Wit reports receipt of unrestricted research grant from Pfizer. Bolkenbaas, Huijts, Mangen and van Werkhoven's research funding is partially supported by grants provided to UMCU by Pfizer. Bolkenbaas, Bonten, Huijts, Mangen, van Werkhoven and de Wit are UMCU employees. No other disclosures were reported.

\section{Consent for publication}

Not applicable.

\section{Ethics approval and consent to participate}

Approval was granted by the Central Committee on Research involving Human Subjects (Ref: NL.24770.041.08). All procedures performed in this study involving human participants were in accordance with the ethical standards of the institutional and/or national research committee and with the 1964 Helsinki declaration and its later amendments or comparable ethical standards.

Trial registration: ClinicalTrials.gov, NCT00812084

\section{Author details}

${ }^{1}$ Julius Center for Health Sciences and Primary Care, University Medical Center Utrecht, Str 6.131 room 7.115, Heidelberglaan 100, Utrecht 3584, CX, The Netherlands. ${ }^{2}$ Department of Respiratory Medicine, University Medical Center Utrecht, Utrecht, The Netherlands. ${ }^{3}$ Department of Medical Microbiology, University Medical Center Utrecht, Utrecht, The Netherlands.

Received: 21 January 2016 Accepted: 9 December 2016

Published online: 06 January 2017

\section{References}

1. Statistics Netherlands. Prognose bevolking; geslacht en leeftijd, 2016-2060. Heerlen. Available at: http://statline.cbs.nl/Statweb/publication/?DM=SLNL\&PA= 83225 ned\&D1=0\&D2=a\&D3=0,131-133\&D4=34\&W=T. Accessed on 8 Sept 2016

2. Brooks R. EuroQol: the current state of play. Health Policy. 1996;37:53-72

3. Brooks R, Rabin R, de Charro F (Eds). The measurement and valuation of health status using EQ-5D: a European perspective - Evidence from the EuroQol BIOMED Research Programme. Kluwer Academic Publishers, 2003. ISBN 978-94-017-0233-1.

4. Brazier JE, Walters SJ, Nicholi JP, Kohler B. Using the SF-36 and Euroqol on an elderly population. Qual Life Res. 1996;5:195-204.

5. Holland R, Smith RD, Harvey I, Swift L, Lenaghan E. Assessing quality of life in the elderly: a direct comparison of the EQ-5D and AQoL. Health Econ. 2004;13:793-805

6. Stolk E, Krabbe P, Busschbach J. Using the Internet to collect EQ-5D norm scores a valid alternative? In: Busschbach j, Rabin R, De Charro F. (Eds.), 24th Scientific Plenary Meeting of the EuroQol Group - Proceedings:153-1 K5: EuroQol Group, 2009.

7. Timmers TK, Verhofstad MHJ, Moons KGM, van Beeck EF, Leenen LPH. Long-term quality of life after surgical intensive care admission. Arch Surg. 2011;146(4):412-7. doi:10.1001/archsurg.2010.279.
8. Szende A, Janssen B, Cabase's J. Self-Reported Population Health: An International Perspective based on EQ-5D. Springer Open; 2014. Available at:http://link.springer com/book/10.1007\%2F978-94-007-7596-1. Accessed on 9 Aug 2016.

9. Hoeymans N, van Lindert H, Westert GP. The health status of the Dutch population as assessed by the EQ-6D. Qual Life Res. 2005;14:655-63.

10. König H-H, Heider D, Lehnert T, Riedel-Heller SG, Angermeyer MC, Matschinger $\mathrm{H}$, et al. Health status of the advanced elderly in six European countries: results from a representative survey using EQ-5D and SF-12. Health Qual Life Outcomes. 2010;8:143. doi:10.1186/1477-7525-8-143.

11. Versteegh M, Vermeulen M, Evers MAA, de Wit GA, Prenger R, Stolk E. Dutch tariff for the five-level version of EQ-5D. Value Health. 2016:19:343-52.

12. Alonso J, Angermeyer MC, Bernert S, Bruffaerts R, Brugha TS, Bryson H, et al. Sampling and methods of the European Study of the Epidemiology of Mental Disorders (ESEMeD) project. Acta Psychiatr Scand Suppl. 2004;420:8-20.

13. Konerding U, Elkhuizen SG, Faubel R, Forte P, Malmstrom T, Pavi E, Janssen MF. The validity of the EQ-5D-3L items: an investigation with type 2 diabetes patients from six European countries. Health Qual Life Outcomes. 2014;12:181.

14. Kontodimopoulos N, Pappa E, Niakas D, Yfantopoulos J, Dimitrakaki C, Tountas Y. Validity of the EuroQoL (EQ-5D) instrument in a Greek general population. Value Health. 2008;11:1162-9.

15. Bernert S, Fernandez A, Haro JM, König HH, Alonso J, Vilagut G, et al. Comparison of different valuation methods for population health status measured by the EQ-5D in three European countries. Value Health. 2009;12:750-8.

16. Savoia E, Fantini MP, Pandolfi PP, Dallolio L, Collina N. Assessing the construct validity of the Italian version of the EQ-5D: preliminary results from a crosssectional study in North Italy. Health Qual Life Outcomes. 2006:4:47.

17. Golicki D, Niewada M. General population reference values for 3-level EQ-5D (EQ-5D-3L) questionnaire in Poland. Pol Arch Med Wewn. 2015;125(1-2):18-26.

18. Kaambwa B, Gill L, McCaffrey N, Lancsar E, Cameron ID, Crotty M, et al. An empirical comparison of the OPQOL-Brief, EQ-5D-3L and ASCOT in a community dwelling population of older people. Health Qual Life Outcomes. 2015;13:164.

19. Perneger TV, Combescure C, Courvoisier DS. General population reference values for the French version of the EuroQol EQ-5D health utility instrument. Value Health. 2010;13(5):631-5. doi:10.1111/j.1524-4733.2010.00727.x.

20. Mangen MJJ, Bonten MJM, de Wit GA. Rationale and design of the costs, health status and outcomes in community-acquired pneumonia (CHO-CAP) study in elderly persons hospitalized with CAP. BMC Infect Dis. 2013;13:597. doi:10.1186/1471-2334-13-597.

21. Hak E, Grobbee DE, Sanders EA, Verheij TJ, Bolkenbaas M, Huijts SM, et al. Rationale and design of CAPITA: a RCT of 13-valent conjugated pneumococcal vaccine efficacy among older adults. Neth J Med. 2008;66(9):378-83.

22. Bonten MJM, Huijts SM, Bolkenbaas M, Webber C, Patterson S, Gault S, et al. Polysaccharide conjugate vaccine against pneumococcal pneumonia in adults. N Engl J Med. 2015;372(12):1114-25. doi:10.1056/NEJMoa1408544.

23. Lamers LM, McDonnell J, Stalmeier PF, Krabbe PF, Busschbach JJ. The Dutch tariff: results and arguments for an effective design for national EQ-5D valuation studies. Health Econ. 2006:15(10):1121-32.

24. Anonymous. Postcodes en provincies. Retrieved from https://nl.wikipedia. org/wiki/Postcodes in Nederland; 2015. Accessed on 3 Sept 2015.

25. Anonymous. First-level NUTS of the European Union. Retrieved from https:// en.wikipedia.org/wiki/First-level_NUTS_of_the_European_Union; 2015. Accessed on 3 Sept 2015.

26. Clemens S, Begum N, Harper C, Whitty J, Scuffham PA. A comparison of EQ-5D-3L population norms in Queensland, Australia, estimated using utility value sets from Australia, the UK and USA. Qual Life Res. 2014;23:2375-81. doi:10.1007/s11136-014-0676-x.

27. König HH, Bernert S, Angermeyer MC, Matschinger H, Martinez M, Vilagut G, et al. Comparison of population health status in six european countries: results of a representative survey using the EQ-5D questionnaire. Med Care. 2009:47:255-61.

28. Anonymous. Goed ervaren gezondheid per GGD-regio. Available at: https:// www.volksgezondheidenzorg.info/onderwerp/ervaren-gezondheid/ regionaal-internationaal/regionaal\#node-goed-ervaren-gezondheid-ggdregio. Accessed on 10 Sep 2016.

29. Statistics Netherlands. Kerncijfers postcodegebieden, 2008-2010. Retrieved from http://www.cbs.nl/nl-NL/menu/informatie/beleid/publicaties/ maatwerk/archief/2012/data-en-toelichting-postcodegebieden-2008-10.htm, 2015. Accessed on 3 Sept 2015 